\title{
Terceirização no setor público: o caso da UESB
}

\author{
Jean da Silva e Silva ${ }^{1}$ \\ Marcos Antônio Tavares Soares ${ }^{2}$
}

\begin{abstract}
Resumo: O presente artigo tem o objetivo de identificar focos de precarização do trabalho terceirizado na UESB, por meio de uma análise comparativa entre os funcionários terceirizados e os servidores efetivos da referida Instituição. Trata-se de um estudo de caso, de caráter exploratório, com abordagem quantitativa. A pesquisa valeu-se de revisão de literatura para constituir o referencial teórico e de levantamento de dados secundários, obtidos por meio da PROAD/UESB e do SINDILIMP/BA. A investigação encontrou os seguintes resultados: 1) os trabalhadores terceirizados da UESB têm jornada de trabalho maior que os servidores efetivos. Enquanto a jornada de trabalho dos efetivos é de 30 ou 40 horas semanais, a dos terceirizados é de 44 horas semanais; 2) os trabalhadores terceirizados recebem menos que os servidores efetivos pelo desempenho de atividades semelhantes. No ano de 2014, os terceirizados ganhavam menos da metade dos efetivos, ou seja, a remuneração dos terceirizados era $50,3 \%$ menor que a dos efetivos. Em 2017 a diferença foi de menos 43,3\%; 3) os trabalhadores terceirizados não possuem a estabilidade que é garantida aos servidores efetivos. Conclui-se, então, que a precarização das condições de trabalho é algo presente no ambiente de trabalho terceirizado da UESB.
\end{abstract}

Palavras-chave: Condições de trabalho. Precarização. Terceirização no setor público.

Abstract: The present article aims to identify precariousness focus in outsourced working conditions at UESB, through a comparative analysis between the outsourced workers and the public servants from it. It is a case study, exploratory, with quantitative approach. The research used the literature review to build the theoretical framework and secondary data collection, obtained through PROAD/UESB and SINDILIMP/BA. The investigation found the following results: 1) the outsourced workers from UESB has a working journey longer than the public servants. While the public servants journey is from 30 to 40 hours per week, the outsourced's 44 hours per week; 2) the outsourced workers from UESB receive less than public servants for the similar activity performance. In the year 2014 the outsourced earned less than half of the public servants, that is, the outsourced remuneration was $50,3 \%$ smaller than the public servants. In 2017 the difference was less than $43,3 \%$; 3) the outsourced workers from UESB does not have the stability witch is guaranteed to the public servants. Then concludes that the precariousness of the working conditions is something present in the UESB outsourced work environment.

Keywords: Work conditions. Precariousness. Outsourcing in the public sector.

\footnotetext{
1 Graduando em Ciências Econômicas pela Universidade Estadual do Sudoeste da Bahia. E-mail: jean_jst@hotmail.com.

2 Mestre em Economia pela Universidade Federal de Campina Grande. Professor de Economia da Universidade Estadual do Sudoeste da Bahia. Pesquisador do NETPS/UESB. E-mail: marcostavarespe@gmail.com.
} 


\section{Introdução}

A terceirização no setor público brasileiro surge no período militar como uma estratégia para redução do tamanho do Estado, mas é na década de 1990, com a adoção dos pressupostos neoliberais, que ela se generaliza e se torna indispensável na visão administrativa da gestão pública, fazendo-se presente em todos os órgãos públicos, inclusive nas instituições de ensino superior. Na UESB, a terceirização é parte integrante da estrutura de pessoal desde 1999. De lá para cá, o número de contratações por essa forma de organização tem aumentado.

Este artigo tem o objetivo de identificar focos de precarização no ambiente de trabalho terceirizado da UESB, considerando três indicadores: jornada de trabalho, remuneração e estabilidade. Busca-se compreender esse fenômeno mediante uma análise comparativa entre as condições de trabalho dos funcionários terceirizados e as dos servidores efetivos, no período de 2014 a 2017.

O presente trabalho possui caráter exploratório. Segundo Gil (2008), "este tipo de pesquisa é realizado especialmente quando o tema escolhido é pouco explorado". Muitas são as pesquisas relacionadas à terceirização no setor privado, porém quando se trata do setor público, objeto deste trabalho, nota-se uma carência de estudos a respeito do tema. A análise classifica-se como estudo de caso, uma vez que se trata de um estudo sobre a UESB. De acordo com Fonseca (2002, apud GERHARDT; SILVEIRA, 2009. p. 39), "um estudo de caso pode ser caracterizado como um estudo de uma entidade bem definida, como um programa, uma instituição, um sistema educativo, uma pessoa, ou uma unidade social". Os dados recebem tratamento quantitativo, visto que são apresentados de forma objetiva e possuem atributos mensuráveis.

O texto está dividido em quatro seções, além desta introdução e da conclusão. A primeira e a segunda seções apresentam alguns destaques, fundamentadas na revisão de literatura e no contexto de desenvolvimento da terceirização no setor público. Tratam, ademais, do seu surgimento e fatores que contribuíram para a sua expansão na UESB. As seções terceira e quarta analisam o fenômeno e sua relação com a precarização, com base nos dados disponibilizados pela Instituição e pelo sindicato que representa parte dos terceirizados.

\section{Terceirização no setor público brasileiro}

O Departamento Intersindical de Estatística e Estudos Socioeconômicos (DIEESE) define a terceirização como "o processo pelo qual uma empresa deixa de executar uma ou mais atividades realizadas por trabalhadores diretamente contratados e as transfere para outra empresa" (DIEESE, 2007, p. 5). Essa definição reflete a visão sindical e de autores que possuem uma postura mais crítica, pois compreendem a terceirização como um dos principais mecanismos de precarização das condições de trabalho. Entre esses autores, destaca-se Marcelino (2008), que formula uma definição mais abrangente, com foco no aspecto social:

[...] terceirização é todo processo de contratação de trabalhadores por empresa interposta, cujo objetivo último é a redução de custos com a força de trabalho. Ou seja, é a relação onde o trabalho é realizado para uma empresa, mas contratado de maneira imediata por outra. Na realidade brasileira, a terceirização é inseparável da 
ampliação da exploração do trabalho, da precarização das condições de vida da classe trabalhadora. E, certamente, ela não teria a abrangência que tem hoje se não fosse a sua capacidade de reduzir custos, de servir como poderoso instrumento para a recomposição das taxas de lucro (MARCELINO, 2008, p. 41, grifo do autor).

No debate atual, o termo terceirização dispõe de diversas definições, inclusive de setores que consideram essa forma de contratação uma estratégia para otimização da produção e da lucratividade, como é o caso dos autores que se apoiam na visão empresarial e economicista. No entanto, uma vez que este artigo se propõe a investigar a terceirização do ponto de vista do trabalho, ou melhor, da precarização deste, considera-se que os conceitos adotados pelo DIEESE (2007) e por Marcelino (2008) melhor interpretam o fenômeno.

De acordo com Reis (2011, p. 78), “a terceirização no setor público nada mais é do que a importação e transferência dos conceitos da terceirização do setor privado para o setor público, com algumas adaptações". É, portanto, a descentralização de serviços que não fazem parte das atividades exclusivas do Estado.

O avanço do processo de terceirização no setor público brasileiro ocorre tal qual no setor privado. Apesar de ter sua gênese na década de 1960, é somente nos anos 1990 que essa prática se consolida no serviço público.

Sabe-se que, salvo casos excepcionais, a contratação de uma empresa privada para prestar serviços especializados ao setor público deve ser precedida de licitação. Segundo o art. $3^{\circ}$ da Lei n ${ }^{\circ} 8.666$ de 1993, "a licitação destina-se a garantir a observância do princípio constitucional da isonomia, a seleção da proposta mais vantajosa para a administração e a promoção do desenvolvimento nacional sustentável" (BRASIL, 1993).

Na visão de Silva (2014), essa Lei foi responsável pela proliferação de contratos de terceiros não somente na esfera federal, mas em todo o país, espalhando-se por estados e municípios. Assim, pode-se dizer que 1990 é a década em que o processo de terceirização se generalizou em todos os segmentos do setor privado e esferas do setor público.

Para Druck (2015), a expansão desmesurada da terceirização no setor público na década de 1990 foi impulsionada também pelos programas de privatização de empresas e de serviços públicos e pela reforma do Estado, iniciada em 1995, por meio do Plano Diretor de Reforma do Aparelho de Estado (PDRAE), de responsabilidade do Ministério da Administração e Reforma do Estado (MARE).

Contribui também para esse processo o Decreto-Lei no 2.271, de 07 de julho de 1997, o qual definiu as atividades que poderiam ser terceirizadas, apresentadas no Art. $1^{\circ}, \$ 1^{\circ}$ da seguinte maneira: "As atividades de conservação, limpeza, segurança, vigilância, transportes, informática, copeiragem, recepção, reprografia, telecomunicações e manutenção de prédios, equipamentos e instalações serão, de preferência, objeto de execução indireta” (BRASIL, 1997).

Além disso, a Lei de Responsabilidade Fiscal, sancionada em 2000 no governo FHC, inibiu a realização de concursos públicos, porque impôs um limite de gastos com pessoal na Administração

\begin{tabular}{|l|c|c|c|c|c|c|c|c}
\hline Cadernos de Ciências Sociais Aplicadas & ano XVII & vol. 17 & $n^{\circ} 29$ & $\begin{array}{c}\text { págs. 161- } \\
178\end{array}$ & jan./jun. 2020 & UESB & Vitória da Conquista/BA & pág. 163 \\
\hline
\end{tabular}


Pública. Desse modo, as instituições públicas intensificaram o uso da terceirização para suprir a necessidade de servidores.

Tudo isso foi parte de uma estratégia pautada nos pressupostos neoliberais, que apontavam para o enxugamento do Estado no que diz respeito ao funcionalismo público. Para lograr êxito na proposta de redução do aparelho do Estado, duas armas foram fundamentais: a privatização, "processo de transformar uma empresa estatal em privada" (BRESSER-PEREIRA, 1997, p. 19); e a publicização, "transformar uma organização estatal em uma organização de direito privado, mas pública não-estatal" (BRESSERPEREIRA, 1997, p. 19). Essas duas estratégias não teriam sido tão contundentes sem a presença da terceirização. Assim, esse aparato (planejado) reduz o tamanho do Estado ao tempo que delimita as suas funções, como pode ser visto no Quadro 1.

\section{Quadro 1 - Instituições resultantes da reforma do Estado}

\begin{tabular}{|c|c|c|c|}
\hline & $\begin{array}{c}\text { Atividades exclusivas de } \\
\text { Estado }\end{array}$ & $\begin{array}{c}\text { Serviços sociais e } \\
\text { científicos }\end{array}$ & $\begin{array}{c}\text { Produção de bens e } \\
\text { serviços para mercado }\end{array}$ \\
\hline $\begin{array}{c}\text { Atividades } \\
\text { principais (Core) }\end{array}$ & $\begin{array}{c}\text { Estado } \\
\text { enquanto pessoal }\end{array}$ & $\begin{array}{c}\text { Entidades públicas não } \\
\text { estatais }\end{array}$ & $\begin{array}{c}\text { Empresas } \\
\text { privatizadas }\end{array}$ \\
\hline $\begin{array}{c}\text { Atividades } \\
\text { auxiliares }\end{array}$ & Empresas terceirizadas & Empresas terceirizadas & Empresas terceirizadas \\
\hline
\end{tabular}

Fonte: Bresser-Pereira (1997, p. 30).

Com a reforma, conforme demonstra o Quadro 1, o Estado somente seria responsável direto por aquelas atividades que lhe são exclusivas, por exemplo, poder de polícia, regulamentação, fiscalização, entre outras. Os serviços sociais e científicos, como universidades, hospitais, centros de pesquisa etc., ficariam sob a responsabilidade das entidades públicas não estatais. Já a produção de bens e serviços para o mercado a cargo das empresas estatais seria privatizada. Por fim, as atividades auxiliares de qualquer setor, independentemente de sua função social, deveriam ser terceirizadas.

\section{Terceirização na UESB}

A Universidade Estadual do Sudoeste da Bahia é uma instituição multicampi com sede localizada na cidade de Vitória da Conquista. Possui mais dois campi, um na cidade de Jequié e outro na cidade de Itapetinga. Trata-se de uma entidade autárquica, dotada de personalidade de direito público e regime especial de ensino, pesquisa e extensão, com autonomia didático-científica, administrativa e de gestão financeira e patrimonial.

Atualmente, a UESB oferta 47 cursos de graduação (22 em Vitória da Conquista, 16 em Jequié e 9 em Itapetinga), sendo 22 cursos de licenciatura e 25 de bacharelado. Conta também com 16 cursos de pós-graduação lato sensu e 27 de pós-graduação strictu sensu, sendo 20 mestrados e 7 doutorados.

No ano de 2017, a instituição contava com 7.942 alunos matriculados nos cursos de graduação nos três campi, mais 2.994 matriculados nos cursos de pós-graduação e no Programa de Formação de Professores. Nesse ano, pertenciam ao quadro de pessoal efetivo 431 servidores técnico-administrativos e 
1.026 professores. A UESB contava ainda com 76 servidores temporários com contrato REDA (54 professores e 22 funcionários de apoio) e 627 funcionários terceirizados em atividades de suporte administrativo, limpeza e segurança.

A terceirização surge na UESB em 1999, sendo as funções de segurança pioneiras nesse processo. A partir de 2003, o governo estadual começou a reestruturar as carreiras dos servidores públicos estaduais, processo que culminou na alteração de nomenclaturas e atribuições, bem como na extinção de cargos, principalmente os de níveis de apoio, como vigilantes, zeladores, serviços gerais, xerografia, motorista, entre outros. Assim, nenhum órgão estadual poderia mais solicitar vagas de concursos públicos para essas funções (CORREIA, 2014 apud FELIX, 2014).

Amparado na Lei no 11.375/2009 (BAHIA, 2009), o governo do Estado reestrutura as carreiras de analista universitário e técnico universitário e as universidades estaduais passam a ter permissão para solicitação de vagas de concurso somente para esses cargos, além, é claro, do cargo de docente. Dessa forma, a UESB passou a funcionar com a seguinte estrutura: as atividades de suporte técnico aos projetos e ações operacionais, administrativos e acadêmicos seriam executadas por analistas e técnicos universitários nomeados mediante concurso público. Serviços auxiliares, como vigilância, conservação e limpeza, motorista, entre outros, seriam executados mediante contratos. Assim, à medida que fossem ficando inativos, os servidores concursados das áreas auxiliares seriam substituídos por trabalhadores terceirizados.

Com a extinção de diversas carreiras de nível operacional e o grande aumento da demanda de serviços, em decorrência da natural expansão da Universidade, foi necessário ampliar as funções do pessoal terceirizado para atender a outras áreas, como suporte e manutenção aos prédios públicos, por exemplo, e contratar telefonistas, agentes de portaria, jardineiros, pedreiros, pintores, marceneiros etc. (CORREIA, 2014 apud FELIX, 2014).

Desse modo, e tal qual ocorre em outros órgãos públicos, a terceirização é um fato crescente na UESB, que sai de 242 funcionários contratados, em 2005, para 627, em 2017. Além dos fatores mencionados no parágrafo anterior, esse aumento está diretamente relacionado ao projeto neoliberal, não abandonado completamente pelos governos petistas, na década de 2000, cuja execução aponta para o enxugamento dos gastos com o funcionalismo público.

\section{Dados sobre a terceirização na UESB}

Os dados referentes ao quantitativo de servidores efetivos foram disponibilizados pela PróReitoria de Administração da UESB (PROAD). Os dos terceirizados foram extraídos dos contratos celebrados entre a UESB e as empresas prestadoras de serviços. Não se tem certeza do número exato de trabalhadores contratados, visto que não se teve acesso a esses dados. Além disso, o contrato prevê que pode haver acréscimos ou supressões de até $25 \%$ no objeto. Por essa razão optou-se por considerar a quantidade máxima prevista em contrato, ou seja, que os contratos foram executados na sua totalidade.

A Tabela 1 mostra que em relação a 2014 o número de servidores efetivos diminuiu, ao passo que o de terceirizados aumentou. No ano de 2014, a UESB contava com 1.532 efetivos. Em 2017, esse

\begin{tabular}{|c|c|c|c|c|c|c|c|c|}
\hline Cadernos de Ciências Sociais Aplicadas & ano XVII & vol. 17 & $n^{\circ} 29$ & $\begin{array}{c}\text { págs. 161- } \\
178\end{array}$ & jan./jun. 2020 & UESB & Vitória da Conquista/BA & pág. 165 \\
\hline
\end{tabular}


quantitativo cai para 1.457, ou seja, em quatro anos, houve uma redução de 4,9\% no quadro de efetivos. Em 2014, eram 579 terceirizados, no ano de 2017 esse número sobe para 627, ou seja, um aumento de $8,3 \%$.

Tabela 1 - Quadro de pessoal da UESB $2014-2017$

\begin{tabular}{lcccc} 
Vínculo/Ano & $\mathbf{2 0 1 4}$ & $\mathbf{2 0 1 5}$ & $\mathbf{2 0 1 6}$ & $\mathbf{2 0 1 7}$ \\
\hline Funcionário efetivo & 472 & 477 & 453 & 431 \\
Professor efetivo & 1.060 & 1.042 & 1.036 & 1.026 \\
Funcionário REDA & 28 & 26 & 24 & 22 \\
Professor REDA & 87 & 70 & 53 & 54 \\
Funcionário terceirizado & 579 & 601 & 551 & 627 \\
\hline TOTAL & 2.226 & 2.216 & 2.117 & 2.182 \\
\hline
\end{tabular}

Fonte: Elaborado pelos autores com base nos dados fornecidos pela PROAD/UESB.

Nota: Os estagiários não foram incluídos nos dados.

A Tabela 1 demonstra ainda que a terceirização corresponde a uma parcela importante do quadro total de pessoal, ficando atrás apenas dos professores, os quais atuam na atividade principal da instituição. Em 2014, os funcionários terceirizados ocupavam 26\% do quadro de pessoal. Já em 2017, a parcela ocupada pelo trabalho terceirizado era de 28,7\%. Quando se excluem os professores (atividadefim) da análise, esse percentual aumenta significativamente, conforme pode ser visualizado na Tabela 2, a seguir:

Tabela 2 - Participação da terceirização no quadro de pessoal da UESB 2014 - 2017, excluídos os professores $(\%)$

\begin{tabular}{lcc} 
Vínculo/Ano & $\mathbf{2 0 1 4}$ & $\mathbf{2 0 1 7}$ \\
\hline Funcionário efetivo & 43,7 & 39,9 \\
Funcionário REDA & 2,6 & 2 \\
Funcionário terceirizado & 53,7 & 58,1 \\
\hline TOTAL & 100,0 & 100,0 \\
\hline
\end{tabular}

Fonte: Elaborado pelos autores com base nos dados fornecidos pela PROAD/UESB.

A Tabela 2 apresenta a participação do trabalho terceirizado no período entre 2014 e 2017 no quadro de pessoal da UESB, não incluídos os professores nesses quantitativos. Essa observação é importante porque os professores fazem parte da atividade principal da instituição, logo, é possível perceber que, nas atividades de suporte e auxiliares, os terceirizados são maioria. Isso significa que a terceirização se torna a principal forma de contratação de trabalhadores para atividades-meio da UESB nos últimos anos. Prova disso é que, em 2017, os terceirizados correspondem a 58,1\% do total; os efetivos, 39,9\%. Em relação a 2014, o número de terceirizados aumentou 8,2\%, enquanto o de efetivos diminuiu $8,7 \%$.

As atividades terceirizadas na UESB entre 2014 e 2017 podem ser divididas em três categorias: suporte administrativo e operacional; manutenção, limpeza e conservação; vigilância e segurança patrimonial. A Tabela 3 apresenta o quantitativo dos postos de trabalho terceirizado por categoria nesse 
período. A categoria que mais empregou foi suporte administrativo e operacional, correspondendo a uma média de 51,6\% nos quatro anos, seguida de manutenção, limpeza e conservação, responsável por 38\% em média dos postos de trabalho. Vigilância e segurança patrimonial ocuparam, em média, 10,5\% dos postos de trabalho terceirizado, como pode ser visto a seguir.

Tabela 3 - Quantidade de postos de trabalho terceirizado por categoria de serviço na UESB $2014-2017$

\begin{tabular}{lcccc} 
Serviço/Ano & $\mathbf{2 0 1 4}$ & $\mathbf{2 0 1 5}$ & $\mathbf{2 0 1 6}$ & $\mathbf{2 0 1 7}$ \\
\hline $\begin{array}{l}\text { Suporte administrativo e } \\
\text { operacional }\end{array}$ & 353 & 270 & 256 & 338 \\
$\begin{array}{l}\text { Manutenção, limpeza e } \\
\text { conservação }\end{array}$ & 163 & 268 & 232 & 232 \\
$\begin{array}{l}\text { Vigilância e segurança } \\
\text { patrimonial }\end{array}$ & 63 & 63 & 63 & 57 \\
\hline TOTAL & $\mathbf{5 7 9}$ & $\mathbf{6 0 1}$ & $\mathbf{5 5 1}$ & $\mathbf{6 2 7}$ \\
\hline
\end{tabular}

Fonte: Elaborado pelos autores com base nos dados fornecidos pela PROAD/UESB.

Para proceder à comparação entre as condições de trabalho dos servidores efetivos e as dos funcionários terceirizados, optou-se por analisar a categoria de suporte administrativo e operacional, visto que, na UESB, são os terceirizados dessa categoria, em especial os cargos de recepcionistas, remanejados para suprir a carência de técnicos universitários.

De acordo com o plano de cargos das universidades, expresso pela Lei Estadual no 11.375/2009 (BAHIA, 2009), o quantitativo de cargos instituído para a UESB é de 553 técnicos universitários. Em 2017, a UESB contava com 301 cargos ocupados, ou seja, 45,57\% das vagas estavam ociosas. Desse modo, a instituição utiliza-se da mão de obra terceirizada para preencher as lacunas no quadro de pessoal da UESB, sem a realização de concurso público.

Como já foi dito, os terceirizados que substituem a mão de obra direta são contratados para as funções de recepção. O trabalhador é contratado e pago pelos serviços de recepcionista, mas na prática, desempenha outras funções na instituição, a exemplo das atividades de suporte técnico aos projetos e ações operacionais e administrativas, as quais são compatíveis com as atribuições do técnico universitário.

De 2014 a 2017, do total de contratações para os serviços terceirizados de suporte administrativo e operacional, $77,8 \%$, em média, foram para as funções de recepção, que se distribuem em três níveis: recepção II, recepção III e recepção IV. De acordo com os editais de licitação, as atribuições são as mesmas para todos os níveis: "realiza a recepção e atendimento telefônico". O critério de diferenciação dos níveis é o grau de formação: o recepcionista nível II deve possuir ensino médio completo e noções de informática; o nível III deve ter ensino médio completo e certificação em curso de informática; e o nível IV deve dispor de ensino superior incompleto, certificação de curso de informática e conhecimento básico em uma língua estrangeira.

O quantitativo de postos de recepção contratados por meio da terceirização no período de 2014 a 2017 está apresentado na Tabela 4, a seguir.

\begin{tabular}{l|c|c|c|c|c|c|c|c}
\hline Cadernos de Ciências Sociais Aplicadas & ano XVII & vol. 17 & $n^{\circ} 29$ & $\begin{array}{c}\text { págs. 161- } \\
178\end{array}$ & jan./jun. 2020 & UESB & Vitória da Conquista/BA & pág. 167
\end{tabular}


Tabela 4 - Quantidade de postos de recepção contratados por meio da terceirização na UESB 2014 - 2017

\begin{tabular}{lcccc} 
Função/Ano & $\mathbf{2 0 1 4}$ & $\mathbf{2 0 1 5}$ & $\mathbf{2 0 1 6}$ & $\mathbf{2 0 1 7}$ \\
\hline Recepção II & 243 & 245 & 180 & 180 \\
Recepção III & 12 & 15 & 12 & 12 \\
Recepção IV & 6 & 10 & 8 & 8 \\
\hline Total & 261 & 270 & 200 & 200 \\
\hline
\end{tabular}

Fonte: Elaborado pelos autores com base nos dados fornecidos pela PROAD/UESB.

É importante destacar que, em média, 91\% dos postos de recepção contratados são para o cargo de recepção II, aquele que exige menos qualificação e, consequentemente, percebe uma remuneração menor. O número de postos de recepção III e recepção IV é, portanto, muito baixo em relação ao total, apenas $9 \%$, em média. Muitas vezes, não obstante a qualificação para os níveis III ou IV, a maioria dos trabalhadores é contratada para o nível II, tendo em vista a disponibilidade de vagas e, principalmente, a sub-remuneração.

Desse modo, e, considerando tanto a proximidade das atribuições quanto a complexidade da função, far-se-á uma comparação entre as atividades desenvolvidas nos postos de recepção II (terceirizados) e as dos técnicos universitários (efetivos). O objetivo é identificar diferenças nas condições de trabalho, bem como a precarização do trabalho na UESB.

Nas pastas do relatório de gestão da PROAD (UESB, 2018) são feitas diversas menções a funcionários terceirizados, os quais assumem funções que, por lei, seriam de competência de um técnico universitário, como ocorre com as atividades de gestão e controle, por exemplo.

Na própria PROAD foram identificados funcionários terceirizados (recepção) com atribuições de suporte de gestão administrativa, acompanhamento de contas e cálculos, acompanhamento e lançamentos no SIMPAS. Essa constitui também a realidade dos demais setores da instituição, conforme consta no relatório (UESB, 2018).

Para a análise comparativa dos servidores efetivos e funcionários terceirizados utilizam-se três indicadores objetivos das condições de trabalho: jornada de trabalho, remuneração e estabilidade no emprego. Esses indicadores contribuem bastante para a identificação de focos de precarização no mundo do trabalho. Eles ajudarão a identificar tais condições no espaço de trabalho da UESB.

Toni (2004) mostra a importância de cada um dos indicadores em sua tese de doutorado. De acordo com a autora, a duração da jornada de trabalho é tomada como expressão de precarização, à medida que são impostas jornadas mais longas de trabalho para uma parcela maior de trabalhadores. Toni considera o rendimento do trabalho, aqui chamado de remuneração, fundamental para a análise, "pois constitui o indicador mais estreitamente relacionado às condições de vida da população em geral e dos trabalhadores em particular" (TONI, 2004, p. 175). Com relação à estabilidade no emprego, a autora trata como instabilidade na ocupação, e ressalta que esta é considerada um indicativo de precarização, “aumentando a insegurança no trabalho e aprofundando a já elevada rotatividade da mão de obra, que constitui uma das marcas de regime de trabalho no Brasil" (TONI, 2004, p. 174). 


\section{Jornada de trabalho}

A análise da jornada de trabalho é feita por meio da apreciação de contratos e leis. O regime de trabalho do servidor público estadual da Bahia subordina-se à Lei Estadual no 6.677/1994 (BAHIA, 1994). A carreira do técnico universitário é regida pela Lei Estadual no 11.375/2009 (BAHIA, 2009). Essas são as duas principais normas que regulamentam o cargo de técnico universitário da UESB. Já o contrato do funcionário terceirizado é regido pela CLT, com cláusulas constantes nos contratos entre a contratante e a contratada e por eventuais cláusulas contratuais estabelecidas entre o terceirizado e o empregador.

O Art. $24^{\circ}$ da Lei no 6.677/1994 define que "o ocupante do cargo de provimento permanente fica sujeito a 30 (trinta) horas semanais de trabalho, salvo quando a lei estabelecer duração diversa" (BAHIA, 1994). Em obediência a esse artigo, o Art. $8^{\circ}$ da Lei no 11.375/2009 estabelece “a jornada de trabalho dos integrantes dos cargos reestruturados por esta Lei é de 30 (trinta) horas semanais" (BAHIA, 2009).

Por interesse da gestão pública, o servidor efetivo pode ter sua jornada de trabalho ampliada, conforme expressa o parágrafo único, Art. $8^{\circ}$ da Lei no 11.375/2009: “a jornada de trabalho poderá ser ampliada a qualquer tempo por interesse da Administração Pública com a anuência do servidor [...]"(BAHIA, 2009). Quando isso acontece, altera-se a jornada para 40 horas semanais. Vale ressaltar que o valor da GSTU ${ }^{3}$ acompanha a carga horária, ou seja, o aumento da jornada de trabalho não implica prejuízo ao servidor, pelo contrário, torna-se um atrativo.

Em 2014, a maioria dos servidores efetivos da UESB submetia-se ao regime de 30 horas semanais. Assim, dos 472 efetivos, 75,2\% tinham uma jornada de trabalho de 30 horas e 24,8\%, 40 horas semanais. Em 2017, os que cumpriam o regime de 30 horas representavam 71,9\% e os de 40 horas, 28,1\%, conforme pode ser observado na Tabela 5 , a seguir.

Tabela 5 - Servidores efetivos da UESB por carga horária semanal 2014-2017

\begin{tabular}{|c|c|c|c|c|}
\hline $\mathrm{CH} /$ Ano & 2014 & 2015 & 2016 & 2017 \\
\hline $30 \mathrm{~h}$ & $35575,2 \%$ & $357 \quad 74,8 \%$ & $337 \quad 74,4 \%$ & $31071,9 \%$ \\
\hline $40 \mathrm{~h}$ & $117 \quad 24,8 \%$ & $120 \quad 25,2 \%$ & $116 \quad 25,6 \%$ & $12128,1 \%$ \\
\hline Total & $472100 \%$ & $477 \quad 100 \%$ & $453 \quad 100 \%$ & $431 \quad 100 \%$ \\
\hline
\end{tabular}

Fonte: Elaborado pelos autores com base nos dados fornecidos pela PROAD/UESB.

A Tabela 5 apresenta o quantitativo de acordo com a carga horária de todos os servidores efetivos, ou seja, os técnicos e analistas universitários. A Instituição não disponibilizou o quantitativo de efetivos por cargo, por esse motivo, não foi possível saber com precisão a quantidade de técnicos universitários no regime de 30 horas para fins comparativos com os terceirizados. Mas, tomando por base a tabela acima, e cientes de que os técnicos representam maior participação no quadro de pessoal efetivo, pode-se afirmar que a quantidade de técnicos universitários com jornada de 30 horas é maior que a quantidade de técnicos com jornada de 40 horas.

${ }^{3}$ Gratificação de Suporte Técnico Universitário.

\begin{tabular}{|c|c|c|c|c|c|c|c|c}
\hline Cadernos de Ciências Sociais Aplicadas & ano XVII & vol. 17 & $n^{\circ} 29$ & $\begin{array}{c}\text { págs. 161- } \\
178\end{array}$ & jan./jun. 2020 & UESB & Vitória da Conquista/BA & pág. 169 \\
\hline
\end{tabular}


Já em relação aos terceirizados, durante o período 2014-2017, a UESB celebrou três contratos para os postos de recepção. Em todos eles, se estabeleceu a jornada de 44 horas semanais. Em 2013, contratou-se a empresa HD Montagens Eletrônicas Ltda. para prestação de serviços de recepção. O contrato $n^{\circ} 033 / 2013$, com a previsão de 261 postos de trabalho e jornada de 44 horas semanais, esteve vigente até outubro de 2014.

Em seguida, a UESB celebrou contrato com a empresa Base Tec Serviços e Empreendimentos Ltda. O contrato $n^{\circ}$ 032/2014 teve vigência de novembro de 2014 a outubro de 2015 e previa a contratação de 270 recepcionistas com jornada de 44 horas. Já em 2016, por meio do contrato ${ }^{\circ}$ 002/2016, o número de postos de trabalho foi reduzido para 200. Esse contrato celebrado entre a UESB e a empresa Know-How Empreendimentos e Serviços Eireli teve vigência até abril de 2018 e a jornada de trabalho prevista era de 44 horas semanais.

Assim, tem-se:

\section{Tabela 6 - Diferença da jornada de trabalho na UESB - terceirizados versus efetivos}

\begin{tabular}{lcc}
\multicolumn{3}{c}{ Horas semanais } \\
\hline Efetivo & 30 & 40 \\
Terceirizado & 44 & 44 \\
\hline Diferença & $\mathbf{4 6 , 7 \%}$ & $\mathbf{1 0 \%}$ \\
Terceirizado/Efetivo &
\end{tabular}

Fonte: Elaborado pelos autores com base nos dados fornecidos pela PROAD/UESB.

Com base nos dados apresentados, chega-se à conclusão de que os funcionários terceirizados são contratados com uma jornada de trabalho maior que os servidores efetivos. Quando se compara a jornada de trabalho semanal dos terceirizados e a jornada dos servidores efetivos enquadrados em 40 horas, observa-se que os terceirizados trabalham 4 horas a mais por semana, o que representa uma diferença de $10 \%$ na jornada. Se o comparativo é feito com os técnicos do regime de 30 horas, que representam a maior parte do quadro, como visto anteriormente, os terceirizados trabalham 14 horas a mais por semana, o que significa uma diferença de $46,7 \%$, conforme a tabela 7 .

A jornada de trabalho é uma cláusula explícita nos contratos entre patrões e funcionários. No setor privado, a jornada, normalmente, é de 44 horas semanais. Já no setor público, a jornada é de 30 ou 40 horas semanais. É o que ocorre no ambiente de trabalho da UESB. Os terceirizados, funcionários de uma empresa privada que presta serviços para a Universidade, têm uma jornada de trabalho maior que os servidores diretos da instituição.

\section{Remuneraşão}

A medida utilizada para se comparar os salários de efetivos e terceirizados é o valor/hora, pois como foi visto no tópico anterior, a carga horária de ambas as categorias diverge. Logo, para a comparação, o valor/hora se torna mais adequado do que o valor mensal. O comparativo é feito entre a remuneração do técnico universitário e a remuneração do cargo de recepção II. Os vencimentos do 
técnico universitário são definidos por lei estadual. Já o piso salarial do terceirizado é definido em convenção coletiva de trabalho.

Para analisar o rendimento do servidor efetivo, foi considerada a remuneração do técnico universitário, ou seja, o vencimento base, acrescido da Gratificação de Suporte Técnico Universitário (GSTU). Está inclusa no cálculo do valor/hora ${ }^{4}$ a GSTU em estágio inicial, ou seja, a gratificação a que faz jus o servidor de grau I, com titulação de nível médio e sem promoção efetivada na carreira.

$\mathrm{Na}$ análise do rendimento do funcionário terceirizado, foi considerada a remuneração ${ }^{5}$ do recepcionista II, estabelecida nas CCTs ${ }^{6}$. De acordo com as CCTs realizadas durante o período em análise, o empregado tem direito a gratificações, adicionais e auxílios. Ainda segundo a CLT, as gratificações e os adicionais são verbas consideradas remuneração, enquanto os auxílios não integram a remuneração do empregado. Desse modo, o auxílio-alimentação, o vale-transporte e as assistências médica e odontológica a que o terceirizado da UESB tem direito, não integram o cálculo do valor/hora.

Os resultados decorrentes dos cálculos acima estão expostos na Tabela 7, abaixo, e mostram um cenário crítico para os funcionários terceirizados da UESB. A condição de trabalho do terceirizado quando o indicador é a remuneração é muito inferior à do efetivo.

Tabela 7 - Remuneração dos servidores efetivos e terceirizados da UESB 2014 - 2017 (valor/hora em R\$)

\begin{tabular}{lcccc} 
Vínculo/Ano & $\mathbf{2 0 1 4}$ & $\mathbf{2 0 1 5}$ & $\mathbf{2 0 1 6}$ & $\mathbf{2 0 1 7}$ \\
\hline Efetivo & 7,90 & 8,17 & 8,60 & 8,60 \\
Terceirizado & 3,93 & 4,32 & 4,83 & 4,87 \\
\hline Diferença & $-50,3 \%$ & $-47,2 \%$ & $-43,9 \%$ & $-43,3 \%$ \\
\hline
\end{tabular}

Fonte: Elaborado pelos autores com base nos dados fornecidos pela PROAD/UESB.

Nota: Foi utilizado o salário vigente no mês de setembro de cada ano.

A tabela 7 acima mostra que em 2014 os terceirizados percebiam menos da metade da remuneração dos efetivos. Enquanto o valor/hora recebido pelo servidor efetivo da UESB era R $\$ 7,90$, o funcionário terceirizado recebia apenas $\mathrm{R} \$ 3,93$ por hora de trabalho, uma diferença de menos 50,3\%. Essa diferença é reduzida nos três anos seguintes, porém, permanece alta. Em 2015, o terceirizado recebia 47,2\% menos que o efetivo, e em 2016 essa diferença diminui para 43,9\%.

É importante observar que o último reajuste salarial concedido à categoria dos técnicos universitários foi em novembro de 2015. Em 2017, a remuneração do servidor efetivo esteve congelada em relação a 2016. Dessa maneira, percebe-se que a redução da diferença de remuneração entre efetivos e terceirizados ocorreu mais em função das perdas salariais dos efetivos do que da melhoria do salário dos terceirizados. Essa constatação fica mais evidente com a leitura da Tabela 8.

Em 2017, a diferença no valor/hora foi de $\mathrm{R} \$ 3$,73. Isso significa que o funcionário terceirizado recebia naquele ano uma remuneração 43,3\% inferior à do servidor efetivo. Esse valor representa uma redução de 7 pontos percentuais em relação a 2014, quando essa diferença era maior.

\footnotetext{
${ }^{4}$ Cálculo do valor/hora do servidor efetivo (30 horas): remuneração/150.

${ }^{5}$ Cálculo do valor/hora do funcionário terceirizado: remuneração/220.

${ }^{6}$ Convenções Coletivas de Trabalho.
}

\begin{tabular}{|c|c|c|c|c|c|c|c|c}
\hline Cadernos de Ciências Sociais Aplicadas & ano XVII & vol. 17 & $n^{\circ} 29$ & $\begin{array}{c}\text { págs. 161- } \\
178\end{array}$ & jan./jun. 2020 & UESB & Vitória da Conquista/BA & pág. 171 \\
\hline
\end{tabular}


A Tabela 8 ajuda a entender o que aconteceu nesse período com a remuneração dos efetivos e terceirizados, levando em consideração a inflação do período e a valorização do salário mínimo.

Tabela 8 - Variação do salário mínimo, das remunerações dos efetivos e terceirizados e inflação acumulada 2014-2017

\begin{tabular}{lcccc} 
& $\mathbf{2 0 1 4}$ & $\mathbf{2 0 1 7}$ & Variação (\%) & $\begin{array}{c}\text { Inflação (INPC) } \\
\text { set.2014 / set.2017 }\end{array}$ \\
\hline Efetivo & 7,90 & 8,60 & 8,8 & \\
Terceirizado & 3,93 & 4,87 & 24,2 & $22,5 \%$ \\
Salário mínimo & 3,29 & 4,26 & 29,5 & \\
\hline
\end{tabular}

Fonte: Elaborado pelos autores com base nos dados fornecidos pela PROAD/UESB.

A tabela 8 mostra a valorização do salário mínimo acima da inflação acumulada do período 2014-2017. Isso ocorreu graças à política de valorização do salário mínimo adotada desde 2004. No mesmo sentido caminhou a remuneração do trabalhador terceirizado, ainda que em magnitude menor, quando houve uma variação de $24,2 \%$ no valor/hora contra uma inflação acumulada de $22,5 \%$ no período. Situação semelhante não se verificou em relação aos servidores efetivos. A variação no valor da hora trabalhada do servidor efetivo foi de apenas $8,8 \%$. Isso representa perda do poder de compra, pois a inflação acumulada do período foi de $22,5 \%$.

Esse fato permite fazer algumas considerações: no período 2014-2017, os servidores efetivos sofreram com a precarização dos seus rendimentos. A remuneração variou muito abaixo da inflação, e o último reajuste salarial concedido à categoria foi em novembro de 2015. Isso ocorreu justamente no contexto de um governo estadual do PT, partido que, no âmbito do governo federal, instituiu a política de valorização do salário mínimo.

Caso o governo estadual tivesse ao menos feito a reposição da inflação para os servidores efetivos, o valor/hora devido a essa categoria, em 2017, seria de $\mathrm{R} \$ 9,68$. Isso significa que a diferença no valor/hora do trabalho dos terceirizados, em comparação com o dos efetivos, seria de $-49,6 \%$. Assim, prevalece o que se constatou anteriormente, a redução no grau de precarização dos trabalhadores terceirizados em relação aos efetivos ocorreu mais em função das perdas salariais dos efetivos do que da melhoria para os terceirizados.

Não se deve ignorar, no entanto, o fato de que os terceirizados tiveram aumento real do poder de compra no período, o que representa uma melhoria das condições de trabalho. Contudo, vale destacar que, não obstante essa pequena melhora relativa, os terceirizados ainda recebem bem menos que os efetivos. Além disso, essa melhoria pode ser questionada, pois se trata aqui de terceirizados contratados para os postos de recepção, mas que, na prática, desempenham funções que, por regra, deveriam ser de responsabilidade dos técnicos universitários. Logo, o que se observa são funcionários terceirizados desempenhando funções de efetivos, no mesmo ambiente de trabalho, com remuneração inferior e sem vínculo empregatício com a Instituição.

O indicador ora analisado aponta para a precarização das condições de trabalho dos terceirizados, no que diz respeito aos rendimentos, pois se verifica que existem na UESB trabalhadores no 
desempenho das mesmas funções, ou semelhantes às dos servidores efetivos, com remuneração inferior. Logo, se torna mais vantajoso, em termos de redução de custos, como advoga o maeinstream econômico, contratar trabalhadores terceirizados do que realizar concurso público.

\section{Estabilidade no emprego}

Optou-se por trabalhar com o termo estabilidade e não rotatividade, visto que o primeiro é mais adequado quando se trata de setor público e a taxa de rotatividade do emprego nos setores que contratam via concurso público é próxima de zero. Essa afirmação se baseia na observação empírica de que o servidor concursado estável só deixará o emprego a pedido e, salvo os casos excepcionais, raramente será demitido, diferentemente do que acontece no setor privado.

A análise da estabilidade no emprego é feita por meio dos contratos e das leis que tratam da matéria. Sabe-se que a estabilidade do servidor público está prevista na Constituição Federal (CF) de 1988 em seu art. 41: "são estáveis após três anos de efetivo exercício os servidores nomeados para cargo de provimento efetivo em virtude de concurso público" (BRASIL, 1988), e tem o objetivo de garantir aos servidores as condições necessárias para o desempenho de suas funções sem sofrer pressões ou intervenções políticas. Igualmente, sabe-se que os trabalhadores do setor privado não possuem estabilidade garantida por lei, exceto em casos excepcionais.

Além da CF, o estatuto dos servidores públicos civis do Estado da Bahia, das autarquias e das fundações públicas estaduais também garante estabilidade ao servidor público estadual. $\mathrm{O}$ art. 28 do referido estatuto determina: "o servidor habilitado em concurso público e empossado em cargo de provimento permanente adquirirá estabilidade ao completar 3 (três) anos de efetivo exercício" (BAHIA, 1994).

Em consonância com a CF, o art. 29 do referido estatuto prevê ainda que "o servidor estável só perderá o cargo em virtude de sentença judicial transitada em julgado ou de processo administrativo disciplinar, desde que lhe seja assegurada ampla defesa" (BAHIA, 1994). Assim, além dos vencimentos do setor público, a estabilidade é um grande atrativo para ingresso na carreira pública.

Já para o setor privado, a garantia de estabilidade só acontece em casos específicos. Com o advento do Fundo de Garantia do Tempo de Serviço (FGTS), a estabilidade decenal, garantida aos trabalhadores com mais de 10 anos de serviço, foi derrogada. Desse modo, as leis que tratam da matéria do trabalho só garantem a estabilidade provisória e em casos específicos, como gestação, acidente de trabalho, pré-aposentados e mais alguns.

Com relação ao trabalho terceirizado na UESB, no período de 2014 a 2017, a Instituição celebrou três contratos para os postos de recepção. Os três foram firmados com diferentes empresas, conforme evidencia o Quadro 2, a seguir:

\begin{tabular}{l|c|c|c|c|c|c|c|c}
\hline Cadernos de Ciências Sociais Aplicadas & ano XVII & vol. 17 & $n^{\circ} 29$ & $\begin{array}{c}\text { págs. 161- } \\
178\end{array}$ & jan./jun. 2020 & UESB & Vitória da Conquista/BA & pág. 173 \\
\hline
\end{tabular}


Quadro 2 - Contratos celebrados entre a UESB e empresas prestadoras de serviços de recepção

\begin{tabular}{|c|c|c|c|}
\hline $\begin{array}{c}\mathbf{N}^{\mathbf{o}} \\
\text { contrato }\end{array}$ & Empresa & Vigência & $\begin{array}{c}\text { Quantidade } \\
\text { de postos de } \\
\text { trabalho }\end{array}$ \\
\hline $033 / 2013$ & HD Montagens Eletrônicas Ltda. & $01 / 09 / 2013$ a $31 / 10 / 2014$ & 261 \\
\hline $032 / 2014$ & $\begin{array}{c}\text { Base Tec Serviços e } \\
\text { Empreendimentos Ltda. }\end{array}$ & $01 / 11 / 2014$ a $31 / 10 / 2015$ & 270 \\
\hline $002 / 2016$ & $\begin{array}{c}\text { Know-How Empreendimentos e } \\
\text { Serviços Eireli }\end{array}$ & $01 / 04 / 2016$ a $30 / 04 / 2018$ & 200 \\
\hline
\end{tabular}

Fonte: Elaborado pelos autores com base nos dados fornecidos pela PROAD/UESB.

Mesmo não dispondo de informações mais precisas sobre os trabalhadores das empresas contratadas pela UESB, com base no Quadro 2, é possível esboçar algumas proposições. Primeiro, os trabalhadores terceirizados são funcionários exclusivos da empresa que ganhou a licitação para a prestação dos serviços e foram contratados sem indicação da UESB. Ao fim do contrato entre a UESB e a empresa, para que o trabalhador mantenha a carteira assinada, é preciso que a empresa tenha o suporte necessário para realocá-lo em outro setor de trabalho, o que é pouco provável acontecer. Não sendo esse o caso, possivelmente o trabalhador é demitido.

Segundo, os trabalhadores das empresas vencedoras da licitação são indicados pela UESB ou a empresa vencedora opte por permanecer com os funcionários da empresa passada. Ao fim do contrato entre a UESB e a empresa, o trabalhador será contratado pela próxima empresa que prestará os serviços. Nesse caso, o trabalhador é demitido da empresa cujo contrato se encerrou e admitido pela nova empresa. Acredita-se que essa segunda opção se adéqua melhor à realidade. Nesse caso, entre um contrato e outro, há alterações no quantitativo de postos de trabalho contratados. Assim, é necessário admitir ou demitir, conforme o caso.

Considerando a segunda ideia mais plausível, o raciocínio segue da seguinte maneira: no contrato com a HD Montagens, em 2013, estava prevista a contratação de 261 recepcionistas. No contrato seguinte, celebrado com a Base Tec, em 2014, a previsão era admitir 270 recepcionistas. Em relação ao primeiro contrato, seria necessário admitir mais 9 trabalhadores. Já no contrato com a Know-How, em 2016, a previsão era de 200 postos de trabalho. Nesse caso, seria preciso demitir 70 trabalhadores. Percebe-se, portanto, uma oscilação no número de trabalhadores contratados, o que leva a crer que no âmbito do trabalho terceirizado da UESB existe uma alta rotatividade de empregados. Enquanto no setor privado a estabilidade é medida pelo tempo de emprego, quanto mais tempo no emprego mais estável o trabalho, no setor público essa é uma questão mais simples. Tem-se ou não a estabilidade.

Desse modo, no ambiente de trabalho da UESB é possível afirmar que os trabalhadores efetivos possuem estabilidade no emprego, enquanto os terceirizados não. Se a interpretação for feita pelo tempo de emprego, é óbvio, porém fundamental afirmar, os trabalhadores terceirizados permanecem menos tempo na UESB do que os efetivos. 


\section{Precarização das condições de trabalho dos terceirizados da UESB}

De acordo com o DIEESE (2007) e Marcelino (2008), a terceirização está diretamente ligada ao processo de precarização do trabalho. Essa é a visão de autores que mantêm uma postura mais crítica a respeito do tema.

Da mesma forma, na visão de Maior (2010), a terceirização no setor público torna evidente o processo de precarização do trabalho, pois a contratação de empresas prestadoras de serviços deve ser necessariamente precedida de licitação, na qual a melhor oferta é avaliada pela modalidade do menor preço. Dessa forma, o custo de ser competitivo no pregão para sagrar-se vencedor reflete na execução do contrato, quando a empresa transfere aos seus empregados o ônus do processo, por meio de condições de trabalho precárias, com o objetivo de manter altas as taxas de lucro. O que acontece na UESB não deve ser algo distante disso.

Os indicadores analisados demonstram que os trabalhadores terceirizados da UESB são contratados sob condições de trabalho inferiores aos servidores efetivos. Essa constatação se baseou na comparação do trabalho das duas categorias, levando em conta a compatibilidade das funções desempenhadas. A pesquisa detectou na Instituição a presença de trabalhadores terceirizados que desempenham basicamente as mesmas funções dos efetivos, com o mesmo grau de complexidade e responsabilidade, porém com jornada de trabalho maior, remuneração menor e sem direito à estabilidade.

É o caso dos funcionários das empresas contratadas para a prestação de serviços de recepção. O trabalhador dessas empresas tem a carteira assinada e exerce um trabalho formal, no entanto, o registro é para o cargo de recepcionista e as condições de trabalho são estabelecidas para tal função. Ocorre que nem todos os trabalhadores contratados para esse fim desempenham, de fato, a função prevista em contrato, sendo realocados para os setores onde há carência de técnicos universitários.

Inicia-se, pois, o processo de precarização, ou seja, quando o trabalhador é contratado para uma função e exerce outras de níveis mais elevados e complexos, sem que as condições de trabalho acompanhem esse movimento. A precarização fica mais evidente quando se analisam os indicadores em separado. Na categoria jornada de trabalho, a análise mostrou que os trabalhadores terceirizados trabalham 4 horas a mais se comparados aos efetivos do regime de 40 horas, e 14 horas a mais se comparados com os efetivos do regime de 30 horas. Eis o primeiro indicativo de precarização das condições de trabalho.

Quanto ao indicador remuneração, os dados demonstram que terceirizados desenvolvendo atividades que, em regra, seriam atribuições dos efetivos, recebem uma remuneração muito inferior. No ano de 2017, os terceirizados recebiam 43,3\% menos que os efetivos. No ano de 2014 , essa diferença era ainda maior, os terceirizados recebiam menos da metade da remuneração dos efetivos. É mais um indicativo de precarização. Por fim, no que diz respeito à estabilidade, ficou demonstrado que, amparados por lei, os efetivos possuem maior estabilidade que os terceirizados. A estabilidade no emprego do servidor efetivo perdura até que este complete o tempo para se aposentar. Esse talvez seja o indicativo mais claro de precarização das condições de trabalho.

\begin{tabular}{|l|c|c|c|c|c|c|c|c|}
\hline Cadernos de Ciências Sociais Aplicadas & ano XVII & vol. 17 & $n^{\circ} 29$ & $\begin{array}{c}\text { págs. 161- } \\
178\end{array}$ & jan./jun. 2020 & UESB & Vitória da Conquista/BA & pág. 175 \\
\hline
\end{tabular}


Nesse cenário, percebe-se que a UESB não está de fora daquilo que fora proposto pelo neoliberalismo, um movimento que assola o país desde a década de 1990. Compreende-se, ademais, que, mesmo em tempos de governos não simpatizantes com a ideologia, as ideias racionalistas continuaram vivas. E, assim, a terceirização foi ganhando um espaço cada vez maior na gestão pública e se tornou um dos principais meios de redução dos gastos com pessoal no setor público.

\section{Conclusão}

Este artigo possibilitou analisar as condições de trabalho dos funcionários terceirizados da UESB em comparação às dos servidores efetivos. O estudo contribui para fortalecer a importância de se ter um pensamento crítico a respeito da terceirização, um tema de forte debate. Perceber a terceirização considerando, além do aspecto econômico, o aspecto social, permite reflexões mais profundas sobre as condições de trabalho daqueles que são marginalizados nesse processo.

Dessa maneira, procurou-se identificar focos de precarização no ambiente de trabalho terceirizado da UESB, com base em três indicadores: jornada de trabalho, remuneração e estabilidade. Para compreender o fenômeno, fez-se uma análise comparativa entre as condições de trabalho de funcionários terceirizados e servidores efetivos, no período de 2014 a 2017.

Verificou-se que a terceirização se consolidou no Brasil na década de 1990, pautada em pressupostos neoliberais, os quais visavam à redução do Estado. A estratégia caiu como uma luva para a redução dos gastos com o funcionalismo público. A UESB seguiu o caminho das demais instituições públicas e, no fim daquela década, passou a utilizar-se do mesmo estratagema. De lá pra cá, a terceirização se tornou a principal forma de contratação de trabalhadores para atividades-meio da Instituição. No ano de 2017, a participação dos terceirizados no quadro de pessoal das atividades-meio da UESB representava $58,1 \%$ do total.

Assim, observa-se que as vagas ocupadas por terceirizados são reais e deveriam fazer parte do quadro permanente, com ingresso via concurso público, pois, desde 2014, o número de admissões por meio de contrato cresce, saltando de 567 para 627, em 2017. Essa evolução confirma que o Estado da Bahia, assim como o setor privado, adotou a racionalidade neoliberal no tocante à gestão dos contratos da força de trabalho para reduzir custos, bem como a pressão da Lei de Responsabilidade Fiscal (LRF).

Constatou-se também que a Universidade não dispõe de servidores efetivos em número suficiente para o bom funcionamento dos setores da instituição e, em virtude disso, os trabalhadores terceirizados, em regra, os contratados para o cargo de recepção II, são alocados para suprir essa carência. Com base nisso, foi possível fazer uma análise comparativa entre terceirizados e efetivos com atribuições compatíveis. Chegou-se aos seguintes resultados:

1) Os trabalhadores terceirizados da UESB têm jornada de trabalho maior que os servidores efetivos. Enquanto a jornada de trabalho dos efetivos é de 30 ou 40 horas semanais, a dos terceirizados é de 44 horas semanais. 
2) Os trabalhadores terceirizados da UESB recebem muito menos que os servidores efetivos. No ano de 2014, os contratados recebiam menos da metade dos efetivos, ou seja, uma remuneração $50,3 \%$ menor que a dos efetivos. Em 2017, essa diferença cai para 43,3\%.

3) Os trabalhadores terceirizados da UESB não possuem estabilidade no emprego, um direito que é garantido por lei aos servidores efetivos.

Identificadas as diferenças das condições de trabalho com base nesses três indicadores, concluise que a precarização está presente no ambiente de trabalho terceirizado da UESB. Também, como foi dito anteriormente, os terceirizados estão ocupando os lugares dos servidores efetivos, porém em condições de trabalho precárias.

Por fim, este trabalho soma-se ao debate sobre a terceirização no setor público, ciente de que tem muito ainda a ser explorado. Espera-se contribuir com estudos futuros a respeito do tema, especialmente quando o objeto for a UESB. É evidente, as contradições nas relações de trabalho terceirizado da UESB e essa discrepância prejudicam não só os terceirizados, mas também o conjunto de trabalhadores. Nesse sentido, observa-se a necessidade de mecanismos de fiscalização e controle sobre as empresas prestadoras de serviços para assegurar os direitos dos trabalhadores terceirizados da UESB.

\section{Referências}

BAHIA. Lei Estadual no 11.375, de 05 de fevereiro de 2009. Reestrutura as carreiras de Analista Universitário e Técnico Universitário, integrantes do Grupo Ocupacional Técnico Específico, criado pela Lei n ${ }^{\circ} 8.889$, de 01 de dezembro de 2003, bem como o seu padrão remuneratório, e dá outras providências. Salvador - BA, 05 fev. 2009.

BRASIL. Lei no 8.666, de 21 de Junho de 1993. Regulamenta o art. 37, inciso XXI, da Constituição Federal, institui normas para licitações e contratos da Administração Pública e dá outras providências. Brasília - DF, 21 jun. 1993.

BRASIL. Decreto-Lei n ${ }^{0}$ 2.271, de 7 de julho de 1997. Dispõe sobre a contratação de serviços pela Administração Pública Federal direta, autárquica e fundacional e dá outras providências. Brasília - DF, 07 jul. 1997.

BRESSER-PEREIRA, Luiz Carlos. A reforma do Estado dos anos 90: lógica e mecanismos de controle. Cadernos MARE da reforma do estado. Ministério da Administração Federal e Reforma do Estado. Brasília, v. 1, 1997. Disponível em: <http://www.bresserpereira.org.br/documents/MARE/CadernosMare/CADERNO01.pdf>. Acesso em: 11 fev. 2019.

DIEESE, Departamento Intersindical de Estatística e Estudos Socioeconômicos. O processo de terceirização e seus efeitos sobre os trabalhadores no Brasil. Relatório técnico. São Paulo: DIEESE/SE/MTE, 2007.

DRUCK, Graça. A terceirização no setor público e a proposta de liberalização da terceirização pelo PL 4330. Blog da Boitempo. Abr. 2015. Disponível em: <https://blogdaboitempo.com.br/2015/04/01/aterceirizacao-no-setor-publico-e-a-proposta-de-liberalizacao-da-terceirizacao-pelo-pl-4330/>. Acesso em: 08 out. 2018.

\begin{tabular}{|l|c|c|c|c|c|c|c|c|}
\hline Cadernos de Ciências Sociais Aplicadas & ano XVII & vol. 17 & $n^{\circ} 29$ & $\begin{array}{c}\text { págs. 161- } \\
178\end{array}$ & jan./jun. 2020 & UESB & Vitória da Conquista/BA & pág. 177 \\
\hline
\end{tabular}


FELIX, Ana Paula dos Santos. Os desafios da gestão de serviços terceirizados na uesb: uma análise sob a ótica dos gestores. 2014. Trabalho de Conclusão de Curso (graduação) - Universidade Estadual do Sudoeste da Bahia, Vitória Conquista, 2014.

GERHARDT, Tatiana Engel; SILVEIRA, Denise Tolfo (Org.). Métodos de Pesquisa. Porto Alegre: Editora da UFRGS, 2009.

GIL, Antônio Carlos. Métodos e técnicas de pesquisa social. $6^{\circ}$ Ed. São Paulo: Atlas, 2008.

MARCELINO, Paula Regina Pereira. Terceirização e Ação Sindical: a singularidade da reestruturação do capital no Brasil. 2008. Tese (Doutorado) - Instituto de Filosofia e Ciências Humanas, Universidade Estadual de Campinas, Campinas, SP, 2008.

REIS, Fátima dos. A Reforma do Estado Brasileiro no Período de 1995 a 2002: reconfiguração da administração e dos serviços públicos e seus reflexos na Universidade Federal de Goiás (UFG). 2011. Dissertação (Mestrado) - Pontifícia Universidade Católica de Goiás, Goiânia, GO, 2011.

SILVA, Luiz Carlos da. Fundamentos da Terceirização na Administração Pública: A Função Teleológica da Terceirização na UFPR. 2014. Dissertação (Mestrado) - Programa de Pós-Graduação em Desenvolvimento Econômico, Universidade Federal do Paraná, Curitiba, PR, 2014. 